\title{
Prevalence and burden of adenomyosis in hysterectomy specimens for benign abnormal uterine bleeding in a tertiary care institute in Pondicherry, India
}

\author{
Vijaya Koothan*, Anitha Vijay, Gayatri Maran, Sreelakshmy
}

\begin{abstract}
Department of Obstetrics \& Gynaecology, Arupadai Veedu Medical College \& Hospital, Kirumampakkam, Pondicherry, India
\end{abstract}

Received: 31 January 2016

Accepted: 01 March 2016

\author{
*Correspondence: \\ Dr. Vijaya Koothan, \\ E-mail: vijayaceline7@gmail.com
}

Copyright: ( ) the author(s), publisher and licensee Medip Academy. This is an open-access article distributed under the terms of the Creative Commons Attribution Non-Commercial License, which permits unrestricted non-commercial use, distribution, and reproduction in any medium, provided the original work is properly cited.

\begin{abstract}
Background: Abnormal uterine bleeding (AUB) is one of the most common presenting complaints encountered by women in reproductive age group. An estimated $60 \%$ of visits to a physician's office are from women seeking treatment for menstrual problems. The aim was to assess the burden and prevalence of adenomyosis among hysterectomy specimens for benign causes of AUB in tertiary care institute in Pondicherry.

Methods: In this retrospective study, records were retrieved of the patients and pathological specimens of consecutive 184 hysterectomies for benign abnormal uterine bleeding done between May 2007 and May 2008. Patient characteristics were retrieved, and the frequency of adenomyosis in this group was determined.

Results: A total of 184 hysterectomies were indicated for benign causes of abnormal uterine bleeding - 50 (23.8\%) for fibroid, $119(55.66 \%$,) for adenomyosis, 15 (7.14\%) for dysfunctional uterine bleeding, endometrial hyperplasia and others, other than for malignant causes. Age range 33-55 years, mean age was 43.62 years among adenomyosis patients

Conclusions: Adenomyosis was diagnosed in 119 (55.66 \%) of the benign AUB specimens. Adenomyosis is a frequent cause for failed conservative management culminating in hysterectomy, posing risk to health related quality of life of women with a bearing on emotional, physical, psychosocial, economic issues and family life.
\end{abstract}

Keywords: Prevalence of adenomyosis, Benign abnormal uterine bleeding, Hysterectomy

\section{INTRODUCTION}

Menstrual disorders are a common indication for medical among women of reproductive lifetime and heavy menstrual bleeding affects up to $30 \% .^{1,2}$ Complaints may significantly affect quality of life time off work, hysterectomy, the health care system. ${ }^{3-6}$

Abnormal uterine bleeding (AUB) is one of the most common presenting complaints encountered by women in reproductive age group. An estimated $60 \%$ of visits to a physician's office are from women seeking treatment for menstrual problems ${ }^{7}$. AUB is defined as a change in frequency of menses, duration of flow, or amount of blood loss. AUB includes heavy menstrual bleeding (i.e., menorrhagia) and can be due to a functional abnormality, organic abnormality (e.g., adenomyosis, fibroids), or systemic disorder (e.g., von Willebrand disease). ${ }^{8}$ Upto $30 \%$ of reproductive age women suffer from menorrhagia. Astha from various studies reports, menorrhagia affects $10-30 \%$ of menstruating women at any one time, and most often during the peri-menopause in unto $50 \%$ of women. The treatment for AUB includes both medical therapies and surgical procedures. ${ }^{9}$ 
Adenomyosis is a benign pathology defined as the presence of endometrial glands and stroma within the myometrium surrounded by hyperplastic and hypertrophic myometrium, which produces growth of the uterus. Adenomyosis is a common cause for heavy menstrual bleeding among patients with AUB. The exact prevalence of adenomyosis in the population is unknown. There are few studies illustrating racial influences of the prevalence of adenomyosis. Before the application of transvaginal ultrasonography in gynaecological practice the diagnosis used to be by histopathology. With the advent of MRI the diagnosis has been more accurate. ${ }^{9}$

The prevalence of adenomyosis reported in the literature varies from $5 \%$ to $70 \%{ }^{10}$ Adenomyosis is more common in multiparous premenopausal and perimenopausal women. Approximately one third of adenomyosis cases are asymptomatic, the rest present as, abnormal bleeding, pelvic pain and uterine growth. ${ }^{11}$ It is not uncommon for the women to resort to hysterectomy for relief of symptoms. What exactly is the palpable burden of adenomyosis among patients with benign causes of AUB, that culminates in hysterectomy is unknown. We embarked on this study in Pondicherry, India to explore the contribution of adenomyosis to non-conservative surgical therapy, very often hysterectomy.

The main aim was to assess the burden and frequency of adenomyosis among hysterectomy specimens for benign causes of AUB in a tertiary care institute in Pondicherry, India.

\section{METHODS}

In this retrospective study, records were retrieved of the patients and pathological specimens of consecutive 184 hysterectomies for benign causes of abnormal uterine bleeding done between May 2007 to May 2008 at Mahatma Gandhi Medical College \& Research Institute, Pondicherry, South India. This is a retrospective study carried out on hysterectomy specimens of subjects who presented to the gynaecologist with the complaint of abnormal uterine bleeding not responding to conservative treatment. Hysterectomies performed for malignant pelvic neoplasms and hysterectomy for utero vaginal prolapse and obstetric causes are excluded. Patient characteristics were retrieved, and the frequency of adenomyosis in this group was determined.

\section{RESULTS}

Cases records of all consecutive cases were retrieved. A total of 184 hysterectomies were indicated for benign causes of abnormal uterine bleeding. The mean parity was 2.6, age range 33-55 years, mean age was 43.62 yearrs among adenomyosis patients.
Table 1: Histopathology diagnosis of hysterectomy specimens of benign causes of AUB.

\begin{tabular}{|ll|}
\hline AUB hysterectomy & $\mathrm{n}=\mathbf{1 8 4}$ \\
\hline Fibroid & $50(23.8 \%)$ \\
\hline Adenomyosis & $119(55.66 \%)$, \\
\hline DUB/ endometrial hyperplasia & $15(7.14 \%)$ \\
\hline
\end{tabular}

\section{DISCUSSION}

The prevalence of adenomyosis in hysterectomy specimens for benign causes of AUB in India varies from $6-55 \%$. In our study, $55 \%$ it is the highest reported in India.

The prevalence of adenomyosis reported depends on, the population studied, out patient department visits to gynaecologic clinics, or established diagnosis from hysterectomy specimens, the method used for diagnosis USG, MRI, \& histopathological assessment. The type of hysterectomy, laparoscopic approach to morcellation might be a cause for under reporting lost in sampling. None of these reflect the exact prevalence in the given population as many women bear with their inconveniences in India until it is unbearable. Some are treated conservatively with medical management and the rest are lost for follow up. Adenomyosis patients often land up with hysterectomy as the last resort owing to non responsive conservative management.

Vercellini et al reported according to two different systematic reviews done in 2006, the prevalence of adenomyosis is thought to be $20 \%-30 \%$ in the general female population.The prevalence amongst women with bleeding disorders is estimated to be closer to $50 \% .^{12}$

Naftalin found adenomyosis in 206 of 985 (20.9\%; $95 \%$ confidence interval (CI) 18.5-23.6\%) among outpatients attending gyaecologic clinic, diagnosed by transvaginal ultrasound. Understandably, this estimate of prevalence of adenomyosis is likely to be higher than in the general population. $^{13}$

In a large series of hysterectomies performed in the Gynecological University Clinic in Tübingen, adenomyosis was diagnosed histologically in $8 \%$ of cases (149 women out of 1955 women who underwent laparoscopic hysterectomy with morcellation). Taran et al reported the likelihood of establishing the diagnosis of adenomyosis was directly proportional to the number of tissue samples taken, with the diagnosis rate varying from 31 to $62 \%$ in the same uterus in morcellated specimen, which means more than half of the diagnosis could be missed. ${ }^{14}$

Maryam et al in a retrospective study of hysterectomy specimens among AUB patients reported the prevalence of adenomyosis $21 \%$, leiomyoma $30 \%$, adenomyosis and leiomyoma $21 \%$, adenomyosis and other pathological 
associations $7 \%$, and other pathological causes $21 \%$. The overall prevalence of adenomyosis was $49 \%$. Mean age of the patients was $46.9 \pm 7.8$ years, figures similar to our our study. ${ }^{15}$

Khreisat et al reported in Jordan found, adenomyosis in 51 women (37\% of cases) out of a total of 138 hysterectomy specimens. Forty- eight of these women $(94 \%)$ were in their forties $(\mathrm{P}>0.05)$, while $49(96 \%)$ were multiparas $(\mathrm{P}<0.05)$. The mean age at hysterectomy was 47.3 years in women with adenomyosis. ${ }^{16}$ Luis Humberto $\mathrm{L}$ et al in center of reproductive medicine, University Hospital, Dr. José Eleute- rio González, Monterrey, México ), reported adenomyosis in 140 out of 794 patients, $17.6 \%$ (95\% CI: 15.120 .4$){ }^{17}$

Chaturvedi V reported in Uttar Pradesh in North India, adenomyosis was 185/827 (22.37\%) and leiomyoma was $22.47 \% 18$; Rizvi G, reported prevalence of adenomyosis as (46.34\%), Mehla S et al 53/218 (46.08\%), Kim and Strawn $(35.2 \%) 64 / 182$, mostly prevalent in the age range of 41- 50 years, like in most studies. ${ }^{11,19.20}$ Gupta $R$ et al reported 390/1596 (24.43\%) of adenomyosis found both $4^{\text {th }}$ and $5^{\text {th }}$ decades equally affected. ${ }^{21}$ In similar studies, Nasir $S$ reported prevalence of adenomyosis were 296/849 34.37\%. ${ }^{22,26}$ Pandey D also reported 21/306 (6.86\%), Ramesh reports 896 of 1827 (49.04\%) irrespective of the preoperative diagnosis, and Karthikeyan et al reports $15.5 \%$ of 90 hysterectomy specimens. $^{23-25}$ Mohammed $\mathrm{N}$ shows a total of 438 gynaecological hysterectomies were performed between 2012-2014, 253 (73\%) were done for AUB. According to Palm Coein proposed by FIGO, AUB-L was the commonest, in 112 (43.7\%) cases, followed by AUB-O57 (22\%), AUB-A 23 (9.1\%). AUB-E-47 (17\%), iatrogenic $2(0.8 \%)$, polyps $5(1.9 \%)$, malignancies and hyperplasias $11(4.3 \%)$ as well. ${ }^{26}$

Studies from Manipal in Karnataka and Coimbatore,India show least preponderance of $6 \%$ unlike in other parts of India , i.e. west, north and south India. Pondicherry suggests highest in India in our study.

\section{$A U B$ at the crux of social problem}

Persistent unpredictable and unscheduled bleeding often lead to psychological, physical, and sexual problems besides cultural issues particularly in India, requiring definitive surgical therapies. In the United States, hysterectomy is the second most common surgery performed - 500,000-600,000/ per annum at a cost of more than $\$ 2$ billion and 200 million euros in Germany 7. Women over the age of 55 years forty percent have under- gone hysterectomy, of which $22 \%$ was for AUB. According to data from the national hospital discharge survey, AUB contributed to more than 5 million hospitalizations, 2 million hysterectomies, and 20 million hospital days in the United States between 1980 and 1992. AUB was the fourth most common gynecologic cause for hospitalisation from 1988 to 1990 , and majority of them, $89 \%$ underwent surgery. AUB accounted for more than 3 million ambulatory day care visits annually from 1999 to 2000 and for more than $20 \%$ of all visits to obstetricians/gynecologists. Mean frequency of adenomyosis contributing to hysterectomy was $20-30 \%$. $^{9}$

\section{Psychological morbidities}

The HRQoL scores from the 36-item short-form health survey questionnaire (SF-36) suggested below the $25^{\text {th }}$ percentile of that for the general female population within a similar age among women with AUB. ${ }^{9}$ Kuppermann et al reported that in women with AUB refractory to hormonal therapy (mean age: 41.8 years), the sexual functioning scores measured by the medical outcomes study sexual problems scales were only 55-69 as compared with 100 (optimal functioning). Greenberg et al showed that mild-to-moderate neurotic depression was found in $62 \%$ of women with AUB in gynecologic clinic. Shaw et al. found that the order of the impacts of menorrhagia (from most important to least important) was family life, physical, occupational, psychological, practical difficulties, and social life. ${ }^{9}$

In 1942 Biskind M, reported nutritional deficiencies and liver dysfunction were associated with less metabolised oestrogen by liver, and the hyper estrogenic state ensuing, causing menorrhagia. The endometrial histopathological examination in thiamine riboflavine deficient patients show, early proliferative phase endometrium to cystic glandular hyperplasia and adenomyosis. ${ }^{27}$ It needs further well planned studies for introspection into the cause and biochemical and histochemical triggering factors for adenomyosis, does socio economic status, nutritional, vitamin deficiencies and malnourishment contribute to hormonal milieu, deranged behaviour of the endometrial epithelium, poor connective tissue support beneath the endometrium that facilitates the invagination into the myometrium is yet to be studied .

\section{Limitations of this study}

The prevalence of adenomyosis among hysterectomy specimens is only the tip of the iceberg, not representative of the prevalence or the burden in the general population as the outpatient management, undetected adenomyosis and the women who have failed to seek health care have not figured in in this study. It is a numerically small representation of the problem, and of a short period study.

\section{CONCLUSION}

AUB is a common cause of health problem in women in reproductive age group. Adenomyosis an entity of AUB is a frequent cause for hysterectomy. The prevalence of adenomyosis in benign lesions of AUB at hysterectomy suggests huge disparities in India, between 6 to 55\%, with varied geographical or racial influences. 
Heavy menstrual bleeding, dyspareunia and dysmenorrhoea could be social problem affecting the woman, physically emotionally. Psychologically, sexually, economically with profound impact on their family lives. Since there is no definitive conservative management for adenomyosis, the community may focus on the risk factors, to avoid radical treatment such as hysterectomy even at a young age. Further research on biochemical changes that influence the histochemical triggering of abnormal proliferation of endometrium may find a clue to conservative management of adenomyosis.

Funding: No funding sources

Conflict of interest: None declared

Ethical approval: The study was approved by the Institutional Ethics Committee

\section{REFERENCES}

1. Kjerulff KH, Erickson BA, Langenberg PW. Chronic gynecological conditions reported by US wom- en: findings from the national health interview survey, 1984 to 1992. Am J Public Health. 1996;86:19.

2. Market Opinion and Research International (MORI). Women's health in 1990. [Research study conducted on behalf of Parke-Davis Laboratories]. London: MORI; 1990.

3. Barnard K, Frayne SM, Skinner KM, Sullivan LM. Health status among women with menstrual symptoms. J Womens Health (Larchmt). 2003;12:911-9.

4. Cote I, Jacobs P, Cumming D. Work loss associated with increased menstrual loss in the United States. Obstet Gynecol. 2002;100:683-7.

5. Millar W. Hysterectomy, 1981/82 to $1996 / 97$. Health Rep. 2001;12:9-22.

6. Frick KD, Clark MA, Steinwachs DM, Langenberg P, Stovall D, Munro MG, et al. Financial and quality-of-life burden of dysfunctional uterine bleeding among women agreeing to obtain surgical treatment. Womens Health Issues. 2009;19:70-8.

7. Schickedanz A, Kalro B, et al. Bleeding problems in mid life. Glob. libr. Women's med. 2008; DOI 10.3843/GLOWM.10297.

8. Singh S, Best C, Dunn S, Leyland N, Wolfman WL, Clinical Practice - Gynaecology Committee, et al Abnormal Uterine Bleeding in Pre-Menopausal Women. J Obstet Gynaecol Can. 2013;35(5):473-9

9. Liu Z, Doan QV, Blumenthal P, Dubois RW. A Systematic Review Evaluating Health-Related Quality of Life,Work Impairment, and Health-Care Costs and Utilizationin Abnormal Uterine Bleeding. Value Health. 2007;10(3):183-94.

10. Saheta A. Abnormal uterine bleeding. Journal of Dental and Medical Sciences. 2014;13(11):63-7.

11. Ghazala R, Pandey H. Histopathological correlation of adenomyosis and leiomyoma in hysterectomy specimens as the cause of abnormal uterine bleeding in women in different age groups in the Kumaon region: A retroprospective study. J Midlife Health. 2013;4(1):27-30.
12. Vercellini P, Viganò $\mathrm{P}$, Somigliana E, Daguati R, Abbiati A, Fedele L. Adenomyosis: epidemiological factors. Best Pract Res Clin Obstet Gynaecol. 2006;20(4):465-77.

13. Naftalin J. How common is adenomyosis? A prospective study of prevalence using transvaginal ultra- sound in a gynaecology clinic. Hum Reprod. 2012;27(12):3432-9.

14. Taran FA, Stewart EA, Brucker S1. Adenomyosis: Epidemiology, risk factors, clinical phenotype and surgical and interventional alternatives to hysterectomy. Gebuurtshife Frauenheild, 2013;73(9);924-31.

15. Mobarakeh MD, Maghsudi A, Rashidi I. Adenomyosis among samples from hysterectomy due to abnormal uterine bleeding in Ahwaz, southern Iran. Adv Biomed Res. 2012;1:49. doi: 10.4103/2277-9175.100156.

16. Khreisat B. Adenomyosis: frequency of hysterectomy in histopathological specimens at two Jordanian military hospitals. JRMS. 2011;18(2):76-9

17. Sordia-Hernandez LH, Herrerob J, Martineza AM, Grisb JM, Rodrigueza DS, Gutierreza OV, et al. Adenomyosis: Pathologies associated in a set of patients un- derwent hysterectomy. Asian Pacific Journal of Reproduction. 2012;1(4):283-6.

18. Chaturvedi V. Pattern and frequency of uterine pathologies among hysterectomy specimens in rural part of northern India: a retrospective secondary data analysis. Ind J Comm Health. 2014;26(1):103-6.

19. Mehla S, Singh M, Chutani N. Clinicopathological correlation of adenomyosis and leiomyoma in hysterectomy specimens as the cause of abnormal uterine bleeding: a retroprospective study sch. J App Med Sci. 2014;2(6G):3320-3.

20. Kim J, Strawn EW. Adenomyosis: A frequent cause of abnormal uterine bleeding. Obstet Gynecol. 2000;95:S23.

21. Gupta R, Dewan D. Clinicopathological Study on Adenomyosis Uteri Paripex- Indian Journal Of Research. 2015;4(3):6-7.

22. Pervez SN, Javed K. Adenomyosis among samples from hysterectomy due to abnormal uterine bleeding. J Ayub Med Coll Abbottabad. 2013;25(1-2):68-70.

23. Pandey D, Sehgal K, Saxena A, Hebbar S, Nambiar J, Bhat RG. An audit of indications, complications, and justification of hysterectomies at a teaching hospital in India. International Journal of Reproductive Medicine. 2014;2014:Article ID 279273.

24. Ramesh BH, Shashikala P, Chandrasekhar D. A Study of Prevalence and Risk Factors of Adenomyosis at Hysterectomy Indian Jou- nalof Public Health Research \& Development. 2013;4(2):203-5.

25. Karthikeyan TM, Veenaa NN, Kumar CRA, Eliz Thomas E. Clinico-pathological study of hysterectomy among rural patients in a tertiary care center, Journal of Dental and Medical Sciences. 2015;14(5):25-7. 
26. Mohammed N, Prejisha B. A study of correlation of etiological and histopathological findings in females undergoing hysterectomy for abnormal uterine bleeding - in accordance with palmcoein classification. Paripex - Indian journal of research. 2014;3(11):76-8.
27. Vitamins and hormones. Vitamins and Hormones. Volume 37. Ed. Harris R, Thimann K.

Cite this article as: Koothan V, Vijay A, Maran G, Sreelakshmy. Prevalence and burden of adenomyosis in hysterectomy specimens for benign abnormal uterine bleeding in a tertiary care institute in Pondicherry, India. Int J Reprod Contracept Obstet Gynecol 2016;5:1119-23. 